\title{
KLASIFIKASI TINGKAT KEKERINGAN PADA DAERAH ALIRAN SUNGAI (DAS) LIMBOTO Classification Of Drought Level In Limboto Watershed
}

\author{
Sri Rahayu Ayuba ${ }^{1}$, Munajat Nurshaputra ${ }^{2}$, Tisen $^{3}$ \\ ${ }^{1,3}$ Program studi Geografi Universitas Muhammadiyah Gorontalo, Indonesia \\ ${ }^{2}$ Universitas Hasanuddin, Indonesia \\ Email korespondensi: srirahayu@umgo.ac.id
}

DOI: http://dx.doi.org/10.31314/jsig.v1i2.174

\begin{abstract}
Changes in land use are the socio-economic forces that most encourage changes and ecosystem degradation. Disruption of the hydrological cycle has caused "3 T" classic problems of water "too much (which causes flooding)," too little (which causes drought) and "too dirty (which causes water pollution). Based on data from BNPB in 1979-2009 there were 8 drought events in Gorontalo Province. This research was carried out in the Limboto Watershed with an area of 86412.6 ha. The method used is the SWAT Method (Soil and Water Assessment Tool) using ArcSwat software that integrates GIS. This research is included in non-experimental research that is by using direct observation in the field. Input of SWAT data include slope, land cover type, climate, and soil type. The analysis used in determining the vulnerability of the watershed to drought is to use the Soil Moisture Deficit Index (SMDI) through the Soil Water (SW) parameter. In this study the use of SWAT model output through ArcSwat, has been able to describe the condition of water supply in the Limboto watershed, which as a whole has been included in the "Vulnerable" category. By comparing the area that experienced drought before and after simulation / running land use directives, it can be concluded that the difference in the area of the watershed that experiences drought with the "Vulnerable" classification is obtained 37,513.1 ha or a decrease of $43.4 \%$ from watershed area.
\end{abstract}

Keywords: Drought, Direction for Land Use, Limboto River Basin, Landing Simulation

\begin{abstract}
Abstrak - Perubahan penggunaan lahan merupakan kekuatan sosial ekonomi yang paling mendorong perubahan dan degradasi ekosistem. Terganggunya siklus hidrologi telah menimbulkan " 3 T" masalah klasik air "too much (yang menimbulkan banjir), "too little (yang menimbulkan kekeringan) dan "too dirty (yang menimbulkan pencemaran air). Berdasarkan data BNPB tahun 1979-2009 terdapat 8 kejadian kekeringan di Provinsi Gorontalo. Penelitian ini dilaksanakan pada Daerah Aliran Sungai (DAS) Limboto dengan luas DAS 86412,6 ha. Metode yang digunakan adalah Metode SWAT (Soil and Water Assessment Tool) dengan menggunakan software ArcSwat yang terintegrasi SIG. Penelitian ini termasuk dalam penellitian non-eksperimen yakni dengan menggunakan pengamatan langsung di lapangan. Input data SWAT antara lain lereng, jenis tutupan lahan, iklim, dan jenis tanah. Analisis yang digunakan dalam menentukan kerentanan DAS terhadap kekeringan adalah dengan menggunakan Soil Moisture Deficit Index (SMDI) melalui parameter Soil Water (SW). Pada penelitian ini penggunaan output model SWAT melalui ArcSwat, telah mampu menggambarkan kondisi pasokan air pada DAS Limboto, yang secara keseluruhan telah termasuk dalam kategori "Rentan". Dengan membandingkan luas area yang mengalami kekeringan pada sebelum dan setelah dilakukan simulasi/running arahan penggunaan lahan maka dapat disimpulkan bahwa selisih luas area DAS yang mengalami kekeringan dengan klasifikasi "Rentan" diperoleh 37.513,1 ha atau secara persentasi mengalami penurunan sebesar 43,4\% dari luas DAS.
\end{abstract}

Kata Kunci: Kekeringan, Arahan Penggunaan Lahan, Daerah Aliran Sungai Limboto, Simulasi Arahan 


\section{PENDAHULUAN}

(UN-WWAP, 2015) menyatakan bahwa, air merupakan inti dari pembangunan berkelanjutan. Perubahan penggunaan lahan bisa dibilang kekuatan sosioekonomi yang paling meluas mendorong perubahan dan degradasi ekosistem (Wu, 2008). Lebih lanjut (Wu, 2008) menyatakan bahwa Deforestasi, pembangunan perkotaan, pertanian, dan kegiatan manusia lainnya telah mengubah bentuklahan Bumi secara substansial. Daerah Aliran Sungai (DAS) menggambarkan bahwa 'sungai' atau 'air' merupakan faktor yang sangat penting dalam pengelolaan DAS (Ruijter \& Agus, 2004). Berdasarkan keputusan (Menteri Kehutanan Republik Indonesia, 2009), Daerah Aliran Sungai (DAS) Limboto Bone Bolango, ditetapkan sebagai DAS dalam kondisi kritis dan memerlukan prioritas penanganan. (Kodoatie, 2010) menyatakan bahwa, terganggunya siklus hidrologi telah menimbulkan "3 T" masalah klasik air "too much (yang menimbulkan banjir), "too little (yang menimbulkan kekeringan) dan "too dirty (yang menimbulkan pencemaran air). Berdasarkan data BNPB tahun 1979-2009 terdapat 8 kejadian kekeringan di Provinsi Gorontalo. Kepala Badan Penanggulangan Bencana Daerah (BPBD) Kabupaten Gorontalo menyatakan bahwa kekeringan sebelumnya terjadi hanya di 11 kecamatan, namun pada bulan Oktober tahun 2015 menjadi 19 kecamatan. Fenomena pemanfaatan lahan untuk kegiatan pertanian ini telah menjadi kegiatan utama yang dilakukan oleh masyarakat sejak dicanangkannya program agropolitan di Provinsi Gorontalo.

Dalam DAS diperlukan perencanaan yang matang guna mencegah segala kemungkinan terburuk, salah satunya adalah dengan pembuatan model perencanaan penggunaan lahan dalam rangka pengendalian kekeringan. Model SWAT mampu mensimulasikan parameter-parameter hidrologi dalam jangka panjang dengan mempertimbangkan karakteristik fisik suatu DAS. Dengan demikian diharapkan DAS Limboto akan mampu mengendalikan berbagai masalah yang ada terutama masalah kekeringan.

\section{METODE DAN DATA}

Penelitian ini menggunakan metode SWAT melalui penggunaan aplikasi ArcSwat. Saat ini model SWAT telah berkembang dengan pesat dengan aplikasi yang sangat beragam mulai dari simulasi hidrologi yang sangat sederhana, simulasi dampak perubahan tata guna lahan, simulasi dampak perubahan iklim bahkan sampai dengan simulasi untuk memprediksikan produktifitas suatu lahan pertanian (Ferijal, 2013). Tahapan dalam penelitian ini, diuraikan sebagai berikut:

A. Teknik Pengumpulan Data

1) Penentuan batas penelitian atau delineasi batas DAS yang digunakan dalam penelitian ini, terdiri dari beberapa tahapan, antara lain:

a) Membuat data Digital Elevation Model (DEM)

b) Mendelinasi DAS

2) Tutupan lahan: Data ini diperoleh dari citra landsat 8 OLI tahun 2016. Setelah interpretasi, dilakukan survey lapangan (ground check) yakni pendetaialan tutupan lahan ke penggunaan lahan. Pada tahap ini masing-masing jenis tutupan lahan (10 titik survey setiap jenis tutupan lahan) yang akan dilakukan pengecekan lapangan dipilih berdasarkan asas keterwakilan dan keterjangkauan lokasi survey.

3) Kelerengan: yakni data yang diperoleh dari citra ASTER GDEM dengan tingkat resolusi 30 Meter.

4) Jenis Tanah: yakni data yang diperoleh dari peta RePPPort

5) Pembentukan HRU ( Hydrological Respone Unit ): data ini diperoleh dari hasil overlay 3 jenis data diatas.

6) Data iklim: yakni data yang diperoleh dari Global Weather.

7) Kalibrasi Output Model SWAT: proses ini akan menyeleraskan hasil output model SWAT dengan hasil perhitungan lapangan. Adapun persamaan yang digunakan Nilai NSE (Nash Sutcliffe Coefficient of Efficiency). Dimana untuk model data debit ditentukan melalui persamaan Nash and Sutcliffe.

B. Teknik Analisis Data

Teknik analisis dalam penelitian ini dikelompokkan dalam 2 tahap analisis, pertama analisis model SWAT menggunakan software ArcSwat dan kedua analisis output model SWAT dalam menentukan kerentanan DAS terhadap kekeringan dengan memanfaatkan ArcGis. Indeks kekeringan merupakan suatu perangkat utama untuk mendeteksi, memantau, dan mengevaluasi 
kejadian kekeringan (Sandi Cahyono, Imam Suprayogi, 2016). Analisis yang digunakan dalam menentukan kerentanan DAS terhadap kekeringan adalah dengan menggunakan Soil Moisture Deficit Index (SMDI). Dengan menggunakan data output hasil model SWAT yakni Soil Water/SW (Kadar Air Tanah). Nilai SW kemudian diolah dalam ArcGis untuk mendapatkan nilai SMDI yang kemudian akan diklasifikasikan dalam klasifikasi SMDI. Adapun formula yang digunakan adalah:

Jika, SW $\leq$ MSW

$$
\text { Maka, } \quad S D=\frac{S W-M S W}{M S W-\min S W} \times 100
$$

Dan jika, SW > MSW

$$
\text { Maka, } \quad S D=\frac{S W-M S W}{\max S W-M S W} \times 100
$$

Dimana:

SD : Defisit kadar air dalam tanah (\%)

SW : Total kadar air dalam tanah pada tahun analisis

MSW : Nilai median dari total kadar air dalam tanah pada periode tahun analisis

Max SW : Nilai maksimum dari total kadar air dalam tanah pada periode tahun analisis

Min SW : Nilai minimum dari total kadar air dalam tanah pada periode tahun analisis

Nilai defisit kadar air dalam tanah (SD) tersebut kemudian dikalkulasikan dalam nilai indeks yakni Soil Moisture Deficit Index (SMDI), menggunakan rumus:

$$
S M D I_{i}=0,5 S M D I_{i-1}+\frac{S D}{50}
$$

Adapun klasifikasi indeks tersebut kemudian dikategorikan seperti pada Tabel 1 berikut.

Tabel 1. Pembobotan Klasifikasi Indeks SMDI

\begin{tabular}{ccccc}
\hline No & Nilai Indeks & Kategori & Tingkat Kerentanan & Bobot \\
\hline 1 & $\geq 4,00$ & Sangat Basah & Tidak Rentan & 1 \\
2 & $3,00 \mathrm{sd} 3,99$ & Basah & Tidak Rentan & 1 \\
3 & $2,00 \mathrm{sd} 2,99$ & Agak Basah & Tidak Rentan & 1 \\
4 & $0,50 \mathrm{sd} 1,99$ & Sedikit Basah & Tidak Rentan & 1 \\
5 & $0,49 \mathrm{sd}-0,49$ & Normal & Tidak Rentan & 1 \\
6 & $-0,50 \mathrm{sd}-1,99$ & Sedikit Kering & Sedikit Rentan & 2 \\
7 & $-2,00 \mathrm{sd}-2,99$ & Agak Kering & Agak Rentan & 3 \\
8 & $-3,00 \mathrm{sd}-3,99$ & Kering & Rentan & 3 \\
9 & $\leq-4,00$ & Sangat Kering & Sangat Rentan & 3 \\
\hline
\end{tabular}

Sumber: (Narasimhan \& Srinivasan, 2005) dalam modifikasi

C. Perumusan Arahan Penggunaan Lahan

Pedoman yang digunakan peneliti dalam mengarahkan penggunaan lahan adalah UU No 37 tentang Konservasi Tanah dan Air yang selaras dengan Peraturan Pemerintah Republik Indonesia Nomor 37 Tahun 2012 tentang Pengelolaan Daerah Aliran Sungai serta pola ruang kabupaten terkait. Arahan yang akan dibuat kemudian akan menghasilkan asumsi mempertahankan perencanaan daerah atau merevisinya.

D. Simulasi Arahan Penggunaan Lahan

Penetuan subDAS/ DAS kecil yang akan diarahkan adalah berdasarkan tingkat 
kerentanan yang diperoleh, yakni dengan perolehan bobot 3, namun arahan penggunaan lahan dilakukan pada seluruh DAS Limboto. Proses ini kembali dilakukan dengan menginput data penggunaan lahan yang kemudian dirunning/simulasi kembali. Hasil running kedua ini kemudian dihitung kembali (persamaan 1-3 dan tabel 1) untuk memperoleh tingkat kerentanan DAS terhadap kekeringan.

\section{HASIL DAN PEMBAHASAN}

Penggunaan Metode SWAT melalui ArcSwat dilakukan untuk memperoleh tingkat kerentanan DAS Limboto terhadap kekeringan. Berbagai output dalam metode ini kemudian diolah dengan berbagai klasifikasi terkait kekeringan pada masing-masing sub DAS/ DAS Kecil. Proses running pada tahap analisis SWAT dilakukan dengan menggunakan software ArcSwat memanfaatkan menu SWAT Simulation. Tahap analisis ini dapat dilakukan apabila tahap Watershed Deliniation, HRU analysis dan Write Input Tabels telah selesai dengan baik. Data yang disimulasi adalah 10 Tahun yakni dari 1 Januari Tahun 2004 hingga 31 Desember 2013 yang mengikuti format data iklim.

Output dari proses running kemudian dianalisis berdasarkan parameter yang menunjukkan tingkat kerentanan DAS terhadap kekeringan. Adapun tahap analisis dalam penelitian ini diuraikan dalam 2 bagian yakni:

A. Analisis Model Soil and Water Asessment Tools (SWAT) Menggunakan Software

ArcSwat.

Penggunaan Metode SWAT melalui ArcSwat diuraikan dalam beberapa tahapan input data berdasarkan klasifikasi SWAT. Input data dalam metode SWAT diuraikan sebagai berikut:

1. Delineasi Batas Daerah Aliran Sungai Limboto

Pada tahap pertama, dilakukan delineasi daerah aliran sungai berdasarkan data Digital Elevation Model (DEM) wilayah DAS yang diteliti. Data DEM yang digunakan pada penelitian ini adalah data ASTER Global DEM dengan resolusi 30 meter. Data kelerengan merupakan data awal yang digunakan dalam tahapan delinease batas DAS. Sehingga parameter yang digunakan adalah parameter DAS dan sub DAS yang dihitung oleh SWAT. Proses delineasi batas DAS dilakukan berdasarkan outlet utama dari ketiga DAS dan outlet masing-masing DAS.

2. Tutupan Lahan DAS Limboto

Data tutupan lahan diperoleh dari BPKH Tahun 2013 yang kemudian di-update dengan menginterpretasi data citra satelit Landsat Tahun 2015. Penggunaan data dengan format rester menjadi salah satu syarat dalam meng-input data tutupan lahan hasil interpretasi. Data ini kemudian diklasifikasikan dalam input model SWAT, yang diuraikan dalam Tabel 1.

Tabel 2. Klasifikasi Tutupan Lahan DAS Limboto

\begin{tabular}{llc}
\hline \multicolumn{1}{c}{ Tutupan Lahan } & Luas (Ha) & Luas $(\%)$ \\
\hline FRST (Hutan Lahan Kering Primer dan Sekunder) & $8.550,6$ & 9,895 \\
ORCD (Perkebunan) & 280,5 & 0,325 \\
URBN (Permukiman) & $2.614,5$ & 3,026 \\
AGRL (Pertanian Lahan Kering dan Campur Semak) & $51.309,8$ & 59,37 \\
RICE (Sawah) & $8.903,8$ & 10.30 \\
RNGB (Semak Belukar) & $11.793,6$ & 13.64 \\
OAK (Tanah Terbuka) & 27.1 & 0.031 \\
WATR (Tubuh Air) & $1.407,1$ & 1.628 \\
WETL (Semak Belukar Rawa) & $1.479,7$ & 1.712 \\
\hline Sumber: Hasil Penelitian & &
\end{tabular}

Sumber: Hasil Penelitian

3. Jenis Tanah

Berdasarkan peta Land System yang diperoleh dari RePPPort, Daerah Aliran Sungai (DAS) Limboto mempunyai jenis tanah seperti yang diuraikan dalam Tabel 3 berikut: 
Tabel 3. Jenis Tanah DAS Limboto

\begin{tabular}{lccc}
\hline Soil_Great & ID Soil & Luas (\%) & Luas (ha) \\
\hline Dystropepts;Humitropepts;Tropohumults & Soil 06 & 10,50 & 9069,6 \\
Dystropepts; Tropudalfs; Haplorthox & Soil 09 & 2,93 & 2534,2 \\
Dystropepts; Tropudalfs; Tropudults & Soil 10 & 4,98 & 4303,7 \\
Dystropepts; Tropudults; Paleudults & Soil 13 & 0,24 & 203,6 \\
Dystropepts; Tropudults; Troperthents & Soil 14 & 36,23 & 31305,4 \\
Dystropepts; Tropudults; Tropudalfs & Soil 15 & 4,69 & 4049,7 \\
Eutropepts & Soil 18 & 4,31 & 3728,6 \\
Eutropepts; Tropudalfs & Soil 21 & 3,72 & 3212,6 \\
Rendolls; Eutropepts & Soil 32 & 9,07 & 7839,3 \\
Tropaquepts; Fluvaquents & Soil 36 & 14,11 & 12196,8 \\
Tropaquepts; Tropofluvents & Soil 39 & 0,77 & 669 \\
Tropaquepts;Tropofluvents; Fluvaquents & Soil 40 & 1,88 & 1625,7 \\
Tropudalfs; Tropudults; Dystropepts & Soil 48 & 1,12 & 966 \\
Tropudults; Tropudalfs; Eutropepts & Soil 59 & 2,09 & 1807,9 \\
Water & WATR & 3,36 & 2900,4 \\
\hline
\end{tabular}

Sumber: Peta RePPPort dan Hasil Penelitian

\section{Pembentukan Hydrological Response Unit (HRU)}

HRU merupakan unit terkecil dalam skala analisis yang dilakukan pada pemodelan SWAT. Setiap lokasi HRU mempunyai tingkat respon yang berbeda terhadap kondisi hidrologinya, misalnya kondisi runoff, erosi, penyimpanan air tanah, aliran bawah tanah, neraca air dan lain sebagainya (Nursaputra, 2015). Unit respon hidrologi adalah bagian dari subbasin yang memiliki atribut penggunaan / pengelolaan / tanah yang unik (Arnold et al., 2011).

Setelah proses delineasi, dilakukan pembentukan HRU (Hydrological Response Unit) dilakukan pada masing-masing DAS. Hal ini bertujuan untuk mendapatkan analisis sub DAS yang digunakan dalam proses running. HRU adalah tahap overlay dari beberapa data, antara lain data DEM, data penggunaan lahan, dan data tanah. Hasil pembentukan HRU mempunyai informasi mengenai penggunaan lahan, tanah, kemiringan lahan, luas area, dan presentasi luas HRU pada sub DAS. DAS Limboto dalam penelitian ini, memperoleh $1701 \mathrm{HRU}, 49$ sub DAS dengan total luas area 86412 ha. Peta hasil pembentukan HRU DAS Limboto disajikan pada Gambar 1.

5. Data Iklim dan Proses Running

Pada penelitian ini, pemasukan data iklim dilakukan untuk mendapatkan keluaran berupa data bulanan hasil simulasi. Data iklim dalam Simulasi SWAT terdiri dari data curah hujan dan suhu pada stasiun yang mewakili daerah DAS, serta data Weather Generator berupa radiasi matahari, kecepatan angin, suhu, curah hujan, dan titik embun. Setelah Penginputan data iklim, dilanjutkan dengan proses running yakni dengan memanfaatkan menu SWAT Simulation.

6. Kalibrasi dan Validasi

Pada tahap ini, penggunaan data debit hasil pengukuran lapangan yang diperoleh dari Balai Besar Sungai Sulawesi II dikalibrasi dengan data debit output model SWAT. Nilai NSE (Nash Sutcliffe Coefficient of Efficiency) untuk model data debit ditentukan melalui persamaan berikut ini (Nash and Sutcliffe, 1970):

$$
\begin{gathered}
N S E=1-\left(\frac{\sum_{i=1}^{n}\left(Q_{O b s, i}-Q_{M o d, i}\right)^{2}}{\sum_{i=1}^{n}\left(Q_{O b s, i}-\bar{Q}_{M o d, i}\right)^{2}}\right) \\
N S E=1-\left(\frac{(1864.52-1.143)^{2}}{(1864.52-0.09)^{2}}\right. \\
N S E=1-(-0.15784) \\
N S E=0.8
\end{gathered}
$$


Efisiensi model NSE dikelompokkan menjadi 3 kelas yaitu "baik" jika NSE $\geq 0,75$, memuaskan jika 0,75 $>$ NSE $\geq 0,36$, dan kurang memuaskan jika NSE $<0,36$ (Moriasi et al dalam Nursahputra, 2015). Dengan kata lain nilai NSE yang diperoleh termasuk kelas "baik" atau terdapat kemiripan antara pola debit yang dihasilkan model dengan pola debit hasil observasi.

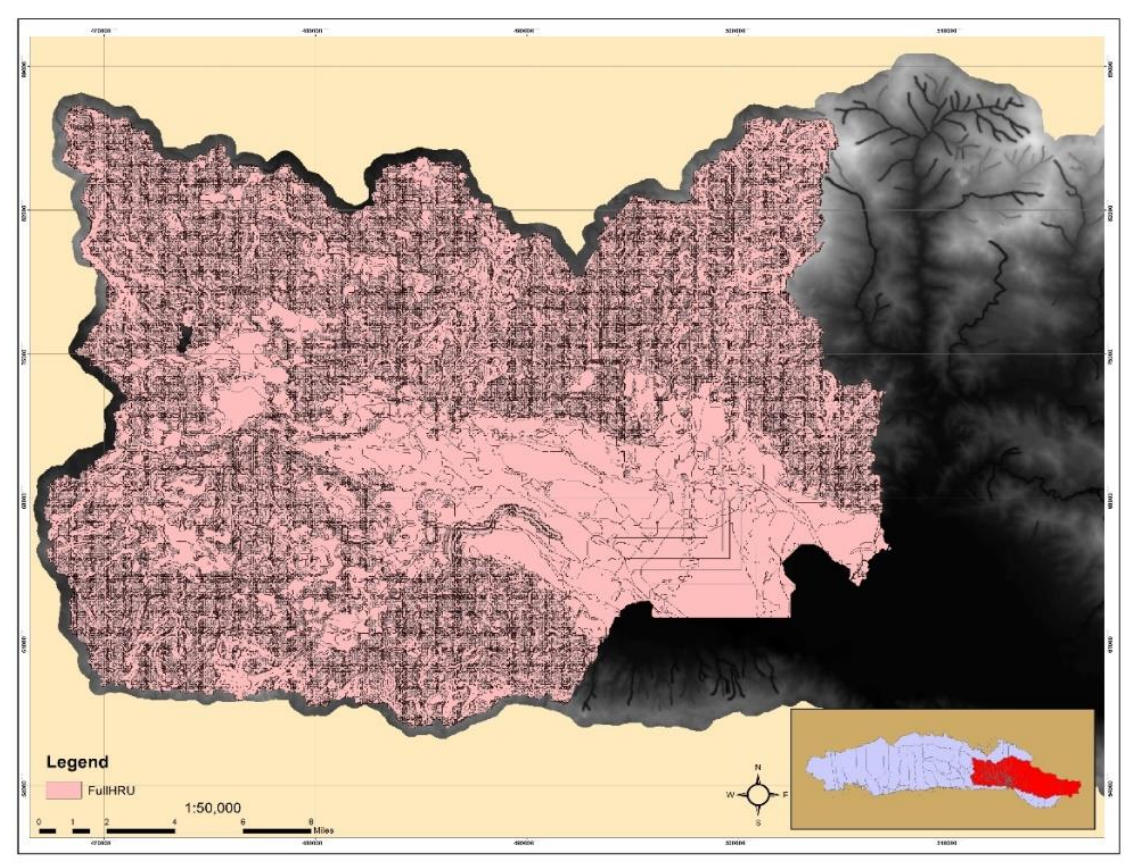

Gambar 1. Peta HRUs DAS Limboto

\section{B. Analisis Output ArcSWAT}

Penentuan kerentanan DAS terhadap kekeringan diperoleh melalui pengolahan output model SWAT dengan penggunaan parameter Soil Water (SW) dalam beberapa persamaan melaui pemanfaatan software ArcGis. Tahap ini secara berurutan menggunakan Persamaan 3 Persamaan 5, sehingga diperoleh nilai/bobot masing-masing sub DAS. Berdasarkan Tabel 4, nilai/bobot yang diperoleh dalam penelitian ini telah menunjukkan tingkat kerentanan DAS dalam 2 kategori klasifikasi, yakni "Rentan" dan "Tidak Rentan".

Tabel 4. Klasifikasi Kekeringan di Sub DAS Limboto

\begin{tabular}{ccc}
\hline Sub DAS & Klasifikasi Kekeringan & Bobot \\
\hline 1 & Rentan & 2 \\
\hline 2 & Rentan & 2 \\
\hline 3 & Rentan & 2 \\
\hline 4 & Rentan & 2 \\
\hline 5 & Rentan & 2 \\
\hline 6 & Rentan & 2 \\
\hline 7 & Rentan & 2 \\
\hline 8 & Rentan & 2 \\
\hline 9 & Rentan & 2 \\
\hline 10 & Rentan & 2 \\
\hline 11 & Rentan & 2 \\
\hline 12 & Rentan & Bobot \\
\hline Sub DAS & Klasifikasi Kekeringan & 2 \\
\hline 13 & Rentan & 2 \\
\hline
\end{tabular}




\begin{tabular}{|c|c|c|}
\hline 14 & Rentan & 2 \\
\hline 15 & Rentan & 2 \\
\hline 16 & Rentan & 2 \\
\hline 17 & Rentan & 2 \\
\hline 18 & Rentan & 2 \\
\hline 19 & Rentan & 2 \\
\hline 20 & Rentan & 2 \\
\hline 21 & Rentan & 2 \\
\hline 22 & Rentan & 2 \\
\hline 23 & Rentan & 2 \\
\hline 24 & Rentan & 2 \\
\hline 25 & Rentan & 2 \\
\hline 26 & Rentan & 2 \\
\hline 27 & Rentan & 2 \\
\hline 28 & Rentan & 2 \\
\hline 29 & Rentan & 2 \\
\hline 30 & Rentan & 2 \\
\hline 31 & Rentan & 2 \\
\hline 32 & Rentan & 2 \\
\hline 33 & Rentan & 2 \\
\hline 34 & Rentan & 2 \\
\hline 35 & Rentan & 2 \\
\hline 36 & Rentan & 2 \\
\hline 37 & Rentan & 2 \\
\hline 38 & Rentan & 2 \\
\hline 39 & Rentan & 2 \\
\hline 40 & Rentan & 2 \\
\hline 41 & Rentan & 2 \\
\hline 42 & Rentan & 2 \\
\hline 43 & Rentan & 2 \\
\hline 44 & Rentan & 2 \\
\hline 45 & Rentan & 2 \\
\hline Sub DAS & Klasifikasi Kekeringan & Bobot \\
\hline 46 & Rentan & 2 \\
\hline 47 & Rentan & 2 \\
\hline 48 & Rentan & 2 \\
\hline 49 & Rentan & 2 \\
\hline
\end{tabular}

Sumber: Hasil Penelitian 


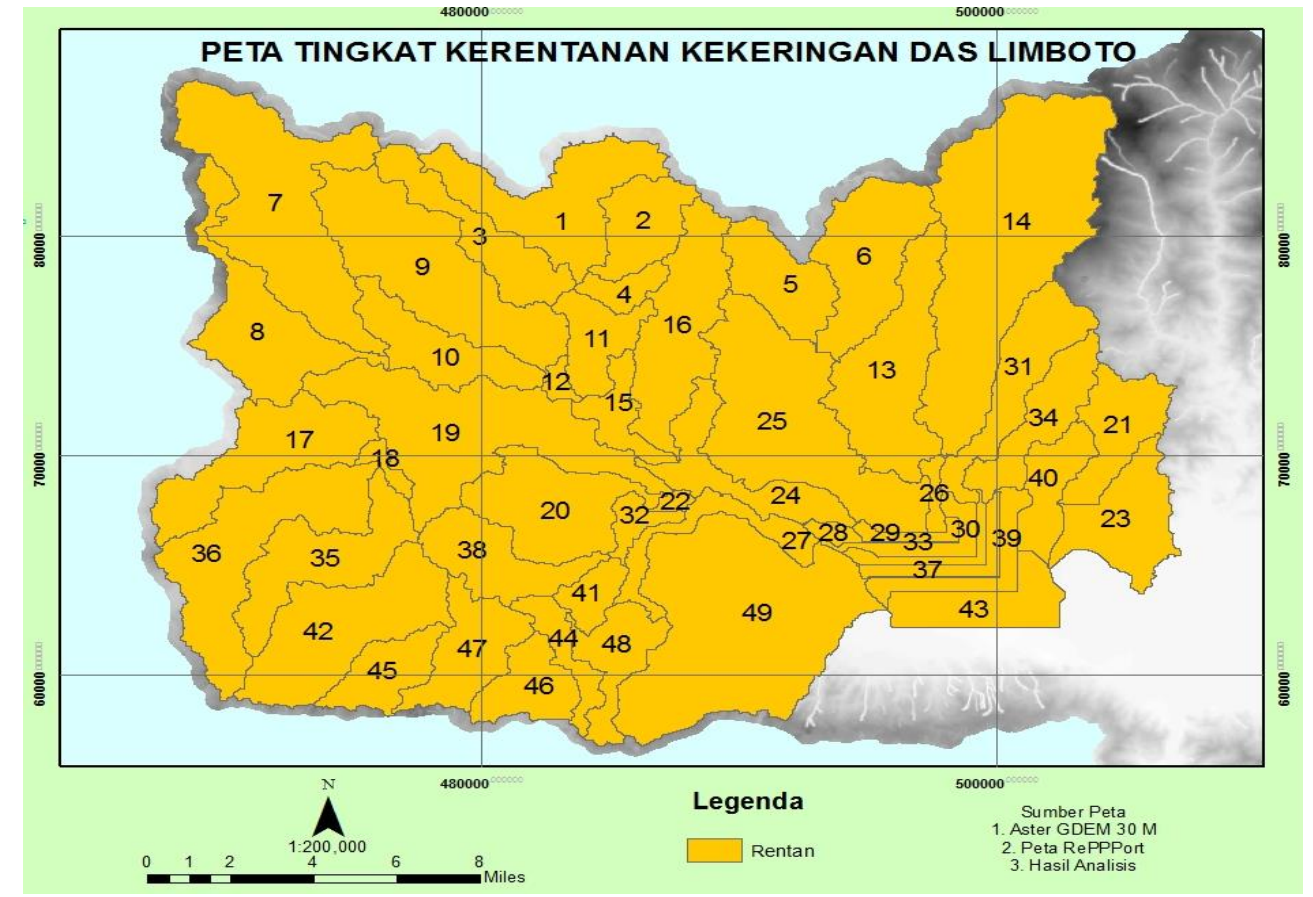

Gambar 2. Peta Tingkat Kerentanan Kekeringan DAS Limboto

Tabel 5. Rekapitulasi Klasifikasi Kekeringan DAS Limboto

\begin{tabular}{llccc}
\hline \multirow{2}{*}{ Nama DAS } & \multicolumn{1}{c}{ Klasifikasi } & $\begin{array}{c}\text { Luas Area } \\
(\mathrm{Ha})\end{array}$ & $\begin{array}{c}\text { Luas Area } \\
(\%)\end{array}$ & $\begin{array}{c}\text { Tersebar pada jumlah Sub } \\
\text { DAS }\end{array}$ \\
\hline \multirow{2}{*}{ Limboto } & Rentan & 86412,6 & 100 & 49 \\
& Tidak Rentan & - & - & - \\
& Total & 86334,2 & 100 & 49 \\
\hline
\end{tabular}

Sumber: Hasil Penelitian

Salah satu indikator suatu DAS telah mengalami penurunan kualitas dan fungsi DAS adalah defisit pasokan air yang mulai terjadi. Analisis yang digunakan dalam menentukan kerentanan DAS terhadap kekeringan adalah dengan menggunakan Soil Moisture Deficit Index (SMDI) melalui parameter Soil Water $(S W)$. Pada penelitian ini penggunaan output model SWAT melalui ArcSwat, telah mampu menggambarkan kondisi pasokan air pada DAS Limboto.

Menurut (Narasimhan \& Srinivasan, 2005), terdapat 9 klasifikasi indeks SMDI. Klasifikasi ini kemudian dikelompokkan kembali dalam 3 kelas yakni "Tidak Rentan", "Rentan", dan "Sangat Rentan". Dalam DAS Limboto, tidak terdapat ketagori "Sangat Rentan". Artinya rata-rata nilai SD (Soil Deficit) hanya berkisar antara $\leq-1,99$ sampai $\geq 4$. Pada DAS Limboto seluruh sub DAS masuk dalam kategori "Rentan". Hal ini menunjukkan bahwa DAS Limboto telah mengalami defisit air secara menyuluruh pada seluruh area sub DAS yang ada. Dari hasil Model SWAT, nilai SMDI DAS Limboto pada Bulan Maret, Mei, dan Agustus dalam 10 Tahun adalah $\geq-2$. Nilai ini dalam klasifikasi Narasimhan \& Srinivasan termasuk kategori "Rentan".

Krisis air bisa terjadi secara temporal yakni krisis air pada bulan-bulan tertentu dalam satu tahun. Terutama akibat terjadinya pergeseran iklim serta kemampuan masing-masing DAS dalam menyimpan dan melepas air (Arsyad, 2010). Guna mencegah kerusakan lingkungan yang tidak hanya menurunkan kualitasnya tapi juga menurunkan kualitas hidup masyarakat setempat, dibutuhkan penanganan efektif dan efisien khususnya pada DAS Limboto yang dalam penelitian ini mempunyai tingkat kerentanan terhadap kekeringan kategori "rentan" yang tersebar dalam 49 sub DAS. 


\section{KESIMPULAN}

Penggunaan lahan eksisiting pada DAS Limboto telah mengindikasikan klasifikasi rentan kekeringan terhadap DAS Limboto, yang tersebar dalam keseluruhan Sub DAS/ DAS Kecil. Guna mencegah kerusakan lingkungan yang tidak hanya menurunkan kualitasnya tapi juga menurunkan kualitas hidup masyarakat setempat, dibutuhkan penanganan efektif dan efisien khususnya pada DAS Limboto yang dalam penelitian ini mempunyai tingkat kerentanan terhadap kekeringan kategori "rentan" yang tersebar dalam 49 sub DAS.

\section{DAFTAR PUSTAKA}

Arnold, J. J., Kiniry, J., Srinivasan, R., Williams, J. R. R., Haney, E. B. B., \& Neitsch, S. L. L., 2011. Soil and water assessment tool: Input/output file documentation version 2009. Texas A M University ..., 662.

Arsyad, S., 2010. Konservasi Tanah dan Air (II). Bogor: IPB.

Cahyono, S, Suprayogi, M. F. I., 2016. Analisis Indeks Kekeringan Menggunakan Metode Thornthwaite Mather Pada Das Siak, (September 2015), 1-15.

Ferijal, T., 2013. Aplikasi Model SWAT Untuk Mensimulasikan Debit Sub DAS Krueng Meulesong Menggunakan Data Klimatologi Aktual dan Data Klimatologi Hasil Perkiraan. Rona Teknik Pertanian, 6(1).

Kodoatie, R. J. dan R. S., 2010. Tata Ruang Air. Yogyakarta: ANDI.

Menteri Kehutanan Republik Indonesia, 2009. Tentang Penetapan Daerah Aliran Sungai (DAS) Prioritas dalam Rangka Rencana Pembangunan Jangka Menengah (RPJM) tahun 20102014. https://doi.org/10.1017/CBO9781107415324.004

Narasimhan, B., \& Srinivasan, R., 2005. Development and evaluation of Soil Moisture Deficit Index (SMDI) and Evapotranspiration Deficit Index (ETDI) for agricultural drought monitoring. Agricultural and Forest Meteorology, 133(1-4), 69-88. https://doi.org/10.1016/j.agrformet.2005.07.012

Nursaputra, M.. 2015. Modul Pelatihan SWAT Menggunakan Arcswat. Makassar.

Ruijter, J., \& Agus, D. F., 2004. Pengelolaan Daerah Aliran Sungai (DAS) Participatory Integrated Development in Rainfed Areas Komponen-komponen dalam pengelolaan DAS. Retrieved from http://www.worldagroforestry.org/sea/Publications/files/leaflet/LE0024-04.pdf.

UN-WWAP, 2015. The United Nations World Water Development Report 2015: Water for a Sustainable World. https://doi.org/978-92-3-100071-3

$\mathrm{Wu}$, J., 2008. The magazine of food, farm, and resource issues Land Use Changes: Economic, Social, and Environmental Impacts. CHOICES 4th Quarter, 23(4).

Wuryanta, A., 2015. Arahan Fungsi Pemanfaatan Lahan Berbasis Daerah Aliran Sungai Sebagai Upaya Pelestarian Lingkungan ( Studi Kasus di Sub DAS Samin ds ). Prosiding Seminar Nasional Innovation in Environmental Management. 